\title{
Adverse radiation effect after stereotactic radiosurgery for brain metastases: incidence, time course, and risk factors
}

\author{
Penny K. Sneed, MD,' Joe Mendez, MD, ${ }^{1}$ Johanna G. M. Vemer-van den Hoek, MD, ${ }^{3}$ \\ Zachary A. Seymour, MD, ${ }^{1}$ Lijun Ma, PhD, ${ }^{1}$ Annette M. Molinaro, PhD, ${ }^{4}$ Shannon E. Fogh, MD, ${ }^{1}$ \\ Jean L. Nakamura, MD, ${ }^{1}$ and Michael W. McDermott, MD ${ }^{1,4}$
}

\begin{abstract}
Departments of ${ }^{1}$ Radiation Oncology and ${ }^{4}$ Neurological Surgery, University of California, San Francisco, California; ${ }^{2}$ Department of Neurology, Washington University in St. Louis School of Medicine, Saint Louis, Missouri; and ${ }^{3}$ Department of Radiation Oncology, University Medical Center Groningen, The Netherlands
\end{abstract}

\begin{abstract}
OBJECT The authors sought to determine the incidence, time course, and risk factors for overall adverse radiation effect (ARE) and symptomatic ARE after stereotactic radiosurgery (SRS) for brain metastases.

METHODS All cases of brain metastases treated from 1998 through 2009 with Gamma Knife SRS at UCSF were considered. Cases with less than 3 months of follow-up imaging, a gap of more than 8 months in imaging during the 1st year, or inadequate imaging availability were excluded. Brain scans and pathology reports were reviewed to ensure consistent scoring of dates of ARE, treatment failure, or both; in case of uncertainty, the cause of lesion worsening was scored as indeterminate. Cumulative incidence of ARE and failure were estimated with the Kaplan-Meier method with censoring at last imaging. Univariate and multivariate Cox proportional hazards analyses were performed.
\end{abstract}

RESULTS Among 435 patients and 2200 brain metastases evaluable, the median patient survival time was 17.4 months and the median lesion imaging follow-up was 9.9 months. Calculated on the basis of 2200 evaluable lesions, the rates of treatment failure, ARE, concurrent failure and ARE, and lesion worsening with indeterminate cause were $9.2 \%, 5.4 \%$, $1.4 \%$, and $4.1 \%$, respectively. Among 118 cases of ARE, approximately $60 \%$ were symptomatic and $85 \%$ occurred $3-18$ months after SRS (median 7.2 months). For 99 ARE cases managed without surgery or bevacizumab, the probabilities of improvement observed on imaging were $40 \%, 57 \%$, and $76 \%$ at 6,12 , and 18 months after onset of ARE. The most important risk factors for ARE included prior SRS to the same lesion (with 20\% 1-year risk of symptomatic ARE vs 3\%, 4\%, and $8 \%$ for no prior treatment, prior whole brain radiotherapy [WBRT], or concurrent WBRT) and any of these volume parameters: target, prescription isodose, 12-Gy, or 10-Gy volume. Excluding lesions treated with repeat SRS, the 1-year probabilities of ARE were $<1 \%, 1 \%, 3 \%, 10 \%$, and $14 \%$ for maximum diameter $0.3-0.6 \mathrm{~cm}, 0.7-1.0 \mathrm{~cm}, 1.1-1.5 \mathrm{~cm}$, $1.6-2.0 \mathrm{~cm}$, and $2.1-5.1 \mathrm{~cm}$, respectively. The 1-year probabilities of symptomatic ARE leveled off at $13 \%-14 \%$ for brain metastases maximum diameter $>2.1 \mathrm{~cm}$, target volume $>1.2 \mathrm{~cm}^{3}$, prescription isodose volume $>1.8 \mathrm{~cm}^{3}, 12$-Gy volume $>3.3 \mathrm{~cm}^{3}$, and 10-Gy volume $>4.3 \mathrm{~cm}^{3}$, excluding lesions treated with repeat SRS. On both univariate and multivariate analysis, capecitabine, but not other systemic therapy within 1 month of SRS, appeared to increase ARE risk. For the multivariate analysis considering only metastases with target volume $>1.0 \mathrm{~cm}^{3}$, risk factors for ARE included prior SRS, kidney primary tumor, connective tissue disorder, and capecitabine.

CONCLUSIONS Although incidence of ARE after SRS was low overall, risk increased rapidly with size and volume, leveling off at a 1-year cumulative incidence of $13 \%-14 \%$. This study describes the time course of ARE and provides risk estimates by various lesion characteristics and treatment parameters to aid in decision-making and patient counseling. http://thejns.org/doi/abs/10.3171/2014.10.JNS141610

KEY WORDS brain metastasis; radiosurgery/adverse effects; radiation injuries; necrosis; dose-response relationship; radiation; brain/radiation effects; stereotactic radiosurgery; oncology

ABBREVIATIONS ARE = adverse radiation effect; $\mathrm{AVM}=$ arteriovenous malformation; $\mathrm{Cl}=$ confidence interval; $\mathrm{HR}=$ hazard ratio; $\mathrm{PACS}=$ picture archiving and communication system; SRS = stereotactic radiosurgery; UCSF = University of California, San Francisco; WBRT = whole-brain radiation therapy.

SUBMITTED July 15, 2014. ACCEPTED October 16, 2014.

INCLUDE WHEN CITING Published online May 15, 2015; DOI: 10.3171/2014.10.JNS141610.

DISCLOSURE The authors report no conflict of interest concerning the materials or methods used in this study or the findings specified in this paper. 
$\mathrm{O}$ NE of the major risks of intracranial stereotactic radiosurgery (SRS) is subsequent development of brain necrosis or adverse radiation effect (ARE). Two large retrospective series reported $4.7 \%-7 \%$ crude overall risk of necrosis resulting in permanent morbidity or requiring craniotomy after SRS for brain metastases. ${ }^{6,12}$ The term necrosis implies an irreversible process, but in some cases, there is temporary enlargement of an enhancing lesion months after SRS, with eventual shrinkage over time. At the onset of radiation injury, it cannot be known whether the changes will be reversible or irreversible. In this paper, we use the term ARE as a more generic term than necrosis, to include both reversible and irreversible radiation injury.

One of the major diagnostic dilemmas on follow-up imaging after SRS for brain metastases is distinguishing between tumor progression and ARE. ${ }^{2}$ These entities can have similar imaging appearance, often as enlarging heterogeneously enhancing or rim-enhancing lesions, complicating treatment decision-making. Commonly, the diagnosis of ARE becomes clear over time, from pathological findings at resection or serial imaging showing shrinkage or stability of the lesion without further treatment, whereas active tumor may be demonstrated by more solid-appearing, sustained growth over multiple follow-up scans. In some cases the diagnosis remains indeterminate, particularly without resection or adequate further imaging.

With the above principles in mind, the purpose of our study was to perform a rigorous, in-depth analysis of the incidence, time course, and risk factors for both overall ARE and symptomatic ARE after SRS for brain metastases. We evaluated a large data set of patients and brain metastases at risk and evaluable for ARE (with $\geq 3$ months of imaging follow-up after SRS) and carefully reviewed serial follow-up imaging to ensure consistent scoring of lesion outcomes.

\section{Methods \\ Study Criteria}

This retrospective review was approved by the Committee on Human Research at the University of California, San Francisco (UCSF). We excluded brain metastases treated with SRS prior to September 1998, as Gamma Knife Model-U plans were difficult to restore for reanalysis, and MRI studies from that era were generally not available on UCSF's picture archiving and communication system (PACS). Other exclusion criteria were absence of follow-up information, less than 3 months of follow-up imaging after SRS, inadequate availability of imaging for review, and a gap of more than 8 months in imaging during the 1st year after SRS (during which radiographic ARE could have appeared and resolved without detection). For brain metastases that demonstrated treatment failure and were re-treated with SRS, each treatment occurrence was included in order to study the risk of ARE at both initial SRS and after repeat SRS to a same lesion. Prior or concurrent radiation was assigned by lesion, not by patient; for example, various brain metastases in a patient managed with SRS alone initially, salvage whole brain radiotherapy (WBRT), and later salvage SRS could have "prior or con- current radiation" coded as none, prior WBRT, or prior SRS + WBRT.

\section{Treatment Technique}

Patients were selected for SRS at a multidisciplinary conference, seen in consultation prior to SRS, and provided informed consent for treatment. On the day of SRS, a Leksell Coordinate Frame $\mathrm{G}$ was affixed by the neurosurgeon under local anesthesia. Contrast-enhanced brain MR images were obtained, targets outlined, and treatment planned using Leksell GammaPlan software (Elekta AB). Prescribed dose was chosen primarily based on treatment volume according to a continuous dose-volume curve posted in the treatment planning area, with 19-20 Gy for prescription isodose volume $<1 \mathrm{~cm}^{3}, 18$ Gy for 4-5 $\mathrm{cm}^{3}, 17 \mathrm{~Gy}$ for $8-9 \mathrm{~cm}^{3}, 16$ Gy for $14-15 \mathrm{~cm}^{3}, 15$ Gy for $22-23 \mathrm{~cm}^{3}$, and in-between doses for in-between volumes, not taking into account prior or concurrent WBRT or prior SRS. It was also our policy to reduce prescription dose by $\sim 1$ Gy for a large number or large total volume of metastases treated in 1 SRS session, and to generally limit prescription dose to 16 Gy for brainstem lesions. Radiosurgical treatment was delivered using the Model B Leksell Gamma Knife from September 1998 through 2001, Model C or 4C from 2002 through October 2007, and the Perfexion Gamma Knife beginning in November 2007. Dexamethasone $(10 \mathrm{mg}$ ) was given intravenously before treatment on the day of SRS to reduce risk of acute effects.

\section{Follow-Up}

Follow-up brain MRI every 3 months was recommended, and patients who underwent imaging elsewhere were asked to send the images to the Gamma Knife Coordinator for review at our weekly SRS conference. UCSF's PACS and routine uploading of outside scans to PACS from compact disks made most institutional and outside imaging performed since the late 1990s readily available for re-review.

\section{Imaging Review}

All available follow-up brain scans were reviewed to ensure consistency. Enlargement of the contrast-enhancing lesion on serial T1-weighted post-gadolinium MRI scans was used to assess for ARE and/or local treatment failure as defined below, scored on the first date of brain imaging showing $\geq 2 \mathrm{~mm}$ increase in lesion diameter or $\geq 25 \%$ increase in the product of 3 orthogonal diameters divided by 2 for irregular lesions $\geq 2 \mathrm{~cm}$ in maximum diameter. Extent of surrounding T2 signal change was not quantitated or used in assessing for ARE or failure, and leukoencephalopathy was not assessed in this study.

\section{Scoring of ARE Versus Local Failure}

In the event of lesion enlargement as defined above, ARE was scored if later surgical intervention confirmed necrosis only, or, in the absence of surgery, if serial imaging showed improvement or stability in the size of the enhancing lesion over time (example shown in Fig. 1). Local failure was scored if later surgical intervention confirmed the presence of tumor cells or, in the absence of surgery, if multiple follow-up scans showed sustained growth of the 


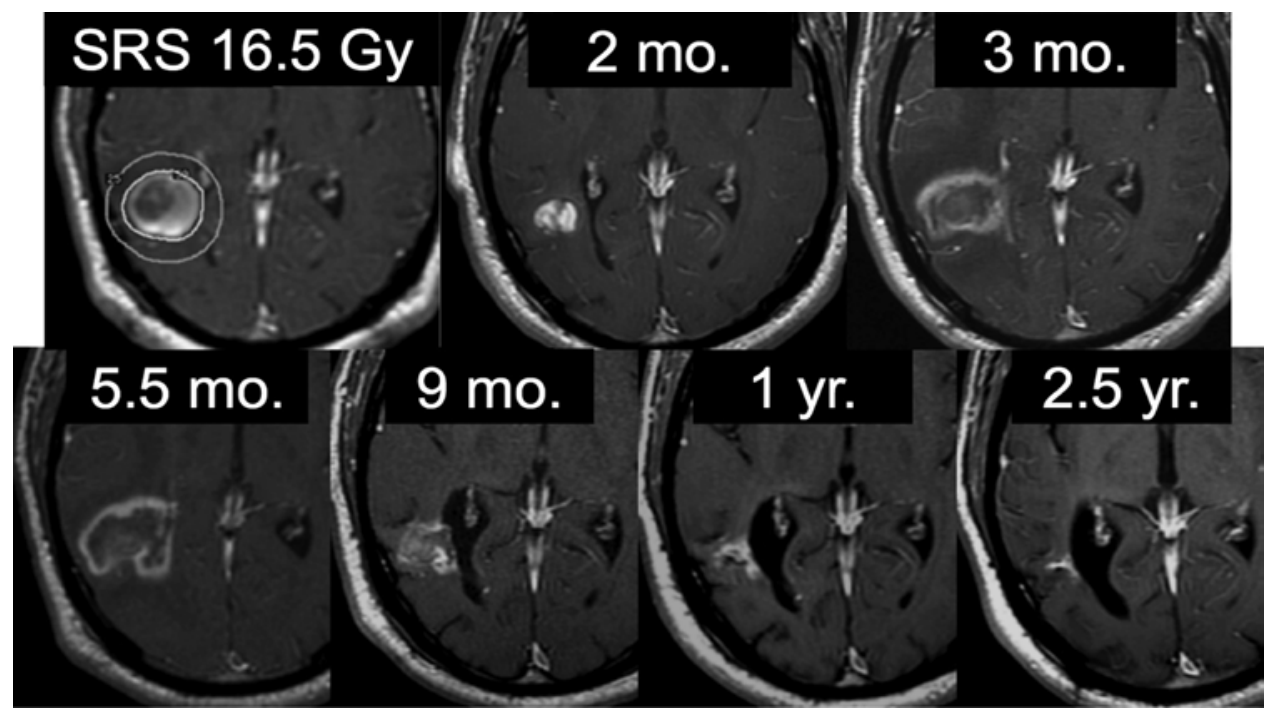

FIG. 1. Case example of ARE scored based on serial contrast-enhanced MRI after SRS treatment of a brain metastasis from renal cell carcinoma. The upper left image from the day of treatment shows the prescription dose contour (16.5 Gy; inner line) and the half-the-prescription-dose contour (outer line). Serial follow-up images show tumor shrinkage at 2 months, onset of ARE at 3 months, worsening of ARE at 5.5 months, then progressive improvement at 9 months, 1 year, and 2.5 years after SRS. This patient had headache and confusion requiring a course of steroids, with tapering over several months.

enhancing lesion. If pathological examination showed both necrosis and tumor, both ARE and failure were scored. Unclear cases were scored as indeterminate, predominantly owing to inadequate further imaging after lesion worsening was first noted. For this study, other techniques such as magnetic resonance spectroscopy, positron emission tomography, and dynamic susceptibility-weighted perfusion MRI were not used in distinguishing between failure and ARE because they were not consistently obtained and their accuracy is uncertain.

\section{Medical Record Review}

In the event of surgical intervention after SRS, operative and pathology reports were reviewed. Medical records were also reviewed retrospectively to abstract additional data: history of hypertension, diabetes, or connective tissue disorder, and systemic therapy given within 1 month before or after SRS. An accounting of all systemic therapy given more than 1 month before or after SRS was deemed infeasible. Details of duration and dosing of steroid therapy for ARE were not generally available.

\section{Dose and Volume Recalculation}

All Gamma Knife plans were restored to recalculate dose parameters using the GammaPlan TMR10 dose calculation algorithm and a fine-calculation dose matrix just large enough to encompass the volume receiving half of the prescription dose. Dose distributions included the dose contribution from all lesions treated in the same SRS session, without adding in any dose contribution from prior WBRT or prior SRS. To account for prior WBRT or SRS, there was an analysis of ARE probability by prior or concurrent radiation (none, prior WBRT, concurrent WBRT, or prior SRS to a same lesion). The 12- and 10-Gy volumes and half-of-prescription-dose volumes were consid- ered to be inevaluable if any of these volumes coalesced with those of nearby lesions. Similarly, the prescription isodose volume was inevaluable if it had any confluence with that of any nearby lesion.

\section{Definitions of ARE Categories}

"ARE" was defined as ARE without failure or ARE occurring more than 6 months before failure, including both symptomatic and asymptomatic cases and including both reversible and irreversible cases.

"ARE \pm failure" was defined as ARE alone, before, or concurrent with failure, excluding the indeterminate cases.

"Worst-case ARE" included the indeterminate cases along with ARE alone, before, or concurrent with failure.

ARE was considered reversible if serial imaging showed shrinkage of the size of the enhancing lesion over time and irreversible if there was no shrinkage over time. Reversibility of ARE imaging changes was time dependent; longer follow-up gave more opportunity for ARE improvement to be observed on imaging. The probability of ARE imaging improvement versus time was calculated by the Kaplan-Meier method for ARE cases not managed surgically or with bevacizumab.

\section{Analysis by Lesion}

Cumulative incidence of ARE and freedom from progression by lesion from the date of SRS were estimated with the Kaplan-Meier method with censoring at last follow-up imaging. For continuous variables such as target volume, 12-Gy volume, and 10-Gy volume, cumulative incidence of ARE was graphed by decile, and then deciles with overlapping curves were combined into fewer risk strata. Similarly, cumulative incidence of ARE was graphed by maximum lesion diameter in $0.5-\mathrm{cm}$ increments, and ranges with overlapping curves were combined 
into fewer risk strata. A cutoff of $0.6 \mathrm{~cm}$ was used for the smallest-diameter subset to include small targets outlined on MRI scans with 3-mm slice thickness.

\section{Analysis by Patient}

Risk factors for ARE by patient were assessed using univariate and multivariate Cox proportional hazards analyses. To account for the repeated observations per patient, we randomly sampled 1 observation per patient and built a univariate Cox proportional hazards model with ARE as the event of interest. This random sampling was repeated 1000 times and the coefficients were averaged. The 95\% confidence intervals (CIs) for the hazard ratios (HRs) were formed assuming a normal approximation. Once the list of variables significant on univariate analysis was established (with HR 95\% CI excluding 1), multivariate models were built via backward model selection. For each model, resampling was repeated 1000 times and variables were removed from the model based on $95 \%$ CIs.

\section{Results}

A total of 899 patients with 4483 brain metastases were treated in one or more Gamma Knife SRS sessions from September 1998 through December 2009. Of these, 435 patients and 2200 brain metastases treated in 600 sessions were evaluable. Excluded were 248 patients with less than 3 months of follow-up imaging, 170 with no follow-up information, 16 with a gap of more than 8 months in imaging during the 1st year, and 30 with inadequate availability of imaging for review.

Patient characteristics for the evaluable cases are provided in Table 1 . The most common primary cancers were lung cancer (175 patients), breast cancer (135), and melanoma (63). The median survival time from the first or only SRS session with brain metastases evaluable for ARE was 17.4 months, compared with 9.8 months among all 899 patients. Fifty-four of the 435 patients were alive at last follow-up, at a median of 57.3 months (range 3.1-168.1 months). The majority of patients (323 [74\%]) had only 1 SRS session (with treatment of a total of 1119 brain metastases); another 79 patients (18\%) had a total of 648 brain metastases treated over 2 sessions, with the remaining 33 patients $(8 \%)$ having up to 6 SRS sessions.

The 435 patients underwent a total of 2886 brain imaging follow-up studies, of which 2812 (97\%) were MRI studies and 2541 (88\%) were re-reviewed on PACS for the current study; 345 other scans were considered evaluable because detailed lesion measurements had been recorded at the time of SRS conference review or detailed reports were available and there was no concern for tumor progression or ARE. By patient, a median of 4 and mean of 6.6 follow-up brain imaging studies were reviewed, and the duration of imaging follow-up ranged from 3.0 to 155.2 months (median 11.1 months, mean 19.9 months). The median and mean imaging follow-up by lesion was 9.9 and 17.8 months.

Lesion characteristics and treatment parameters are shown in Table 2 . The median value for prescribed dose was $19 \mathrm{~Gy}$, maximum target diameter $0.9 \mathrm{~cm}$, target volume $0.189 \mathrm{~cm}^{3}$, prescription isodose volume $0.394 \mathrm{~cm}^{3}$, and 12-Gy volume $0.947 \mathrm{~cm}^{3}$. Table 3 describes dose and
TABLE 1. Demographic and clinical characteristics for 435 patients with 2200 evaluable brain metastases*

\begin{tabular}{|c|c|}
\hline Characteristic & Value \\
\hline \multicolumn{2}{|l|}{ Primary tumor } \\
\hline Breast cancer & $135(31 \%)$ \\
\hline Lung cancer & $175(40 \%$ \\
\hline Melanoma & $63(14 \%)$ \\
\hline Kidney cancer & $26(6 \%)$ \\
\hline Sarcoma & $6(1 \%)$ \\
\hline Thyroid cancer & $6(1 \%)$ \\
\hline Other/unknown & $24(6 \%)$ \\
\hline \multicolumn{2}{|l|}{ Age in yrs } \\
\hline Median & 55 \\
\hline Range & $6-86$ \\
\hline \multicolumn{2}{|l|}{ KPS score } \\
\hline Median & 90 \\
\hline Range & $40-100$ \\
\hline \multicolumn{2}{|l|}{ Sex } \\
\hline Female & $281(65 \%$ \\
\hline Male & $154(35 \%$ \\
\hline \multicolumn{2}{|l|}{ RTOG RPA class } \\
\hline 1 & $60(14 \%)$ \\
\hline 2 & $355(82 \%$ \\
\hline 3 & $20(5 \%)$ \\
\hline \multicolumn{2}{|l|}{ Comorbidities } \\
\hline Hypertension & $112(26 \%$ \\
\hline Diabetes & $26(6 \%)$ \\
\hline Connective tissue disorder & $10(3 \%)$ \\
\hline \multicolumn{2}{|c|}{$\begin{array}{l}\text { No. of ARE-evaluable brain metastases/pts treated, by } \\
\text { no. of SRS sessions }\end{array}$} \\
\hline 1 session & $1119 / 323$ \\
\hline 2 sessions & $648 / 79$ \\
\hline 3 sessions & $182 / 18$ \\
\hline 4 sessions & $136 / 12$ \\
\hline 5 sessions & $21 / 1$ \\
\hline 6 sessions & $94 / 2$ \\
\hline \multicolumn{2}{|l|}{ Imaging follow-up in all 435 pts (mos) $†$} \\
\hline Median & 11.1 \\
\hline Range & $3.0-155.2$ \\
\hline \multicolumn{2}{|l|}{ Clinical follow-up in 54 living pts (mos) $†$} \\
\hline Median & 57.3 \\
\hline Range & $3.1-168.1$ \\
\hline Median survival time (mos) $\dagger$ & 17.4 \\
\hline
\end{tabular}

KPS = Karnofsky Performance Scale; pts = patients; RPA = recursive partitioning analysis; RTOG = Radiation Therapy Oncology Group.

* Values represent numbers of patients (\%) unless otherwise indicated.

$\dagger$ Measured from the date of the first or only SRS treatment.

target volume by prior or concurrent radiation (none, prior WBRT, concurrent WBRT, or prior SRS to a same lesion). Gradient index ${ }^{11}$ and Paddick conformity index ${ }^{10}$ were correlated with maximum diameter, with median values of $3.54,3.27,3.12,2.89$, and 2.82 and $0.31,0.44,0.62,0.71$, 
TABLE 2. Brain metastasis characteristics and treatment parameters for 2200 evaluable metastases

\begin{tabular}{|c|c|}
\hline Characteristic & Value* \\
\hline \multicolumn{2}{|l|}{ Primary site } \\
\hline Breast & $920(42 \%)$ \\
\hline Lung & $750(34 \%)$ \\
\hline Melanoma & $300(14 \%)$ \\
\hline Kidney & $86(4 \%)$ \\
\hline Sarcoma & $43(2 \%)$ \\
\hline Thyroid & $49(2 \%)$ \\
\hline Other/unknown & $52(2 \%)$ \\
\hline \multicolumn{2}{|l|}{ Associated comorbidities } \\
\hline Hypertension & $444(20 \%)$ \\
\hline Diabetes & $122(6 \%)$ \\
\hline Connective tissue disorder & $40(2 \%)$ \\
\hline \multicolumn{2}{|c|}{ Systemic therapy w/in 1 mo (no/yes/unknown) } \\
\hline Any & $664(30 \%) / 1289(59 \%) / 247(11 \%)$ \\
\hline Cytoxic & $1103(50 \%) / 830(38 \%) / 267(12 \%)$ \\
\hline Inhibitor & $1733(79 \%) / 193(9 \%) / 269(12 \%)$ \\
\hline Antibody & $1445(66 \%) / 485(22 \%) / 265(12 \%)$ \\
\hline Immunomodulator & $2162(98 \%) / 38(2 \%) / 0$ \\
\hline \multicolumn{2}{|l|}{ Location } \\
\hline Supratentorial lobar & $1634(74 \%)$ \\
\hline Supratentorial deep & $88(4 \%)$ \\
\hline Cerebellum & $447(20 \%)$ \\
\hline Brainstem & $31(1 \%)$ \\
\hline \multicolumn{2}{|l|}{ Prior or concurrent radiation } \\
\hline None & $1182(54 \%)$ \\
\hline Prior WBRT & $779(35 \%)$ \\
\hline Concurrent WBRT & $167(8 \%)$ \\
\hline Prior SRS to same lesion $\pm \mathrm{RT}$ & $72(3 \%)$ \\
\hline Prior surgery & $47(2 \%)$ \\
\hline \multicolumn{2}{|l|}{ Prescribed dose (Gy) } \\
\hline Range & $7.5-20.0$ \\
\hline Median & 19.0 \\
\hline 25th percentile & 18.0 \\
\hline \multicolumn{2}{|l|}{ Prescribed isodose contour (\%) } \\
\hline Range & $30-98$ \\
\hline Median & 58 \\
\hline 25th percentile & 50 \\
\hline \multicolumn{2}{|l|}{ Max diameter $(\mathrm{cm})$} \\
\hline Range & $0.3-5.1$ \\
\hline Median & 0.9 \\
\hline 75th percentile & 1.5 \\
\hline \multicolumn{2}{|l|}{ Target vol $\left(\mathrm{cm}^{3}\right)$} \\
\hline Range & $0.006-13.15$ \\
\hline Median & 0.189 \\
\hline 75th percentile & 0.844 \\
\hline \multicolumn{2}{|c|}{ Prescription isodose vol $\left(\mathrm{cm}^{3}\right)(\mathrm{n}=2049)$} \\
\hline Range & $0.014-37.36$ \\
\hline Median & 0.394 \\
\hline 75th percentile & 1.38 \\
\hline
\end{tabular}


TABLE 2. Brain metastasis characteristics and treatment parameters for 2200 evaluable metastases (continued)

\begin{tabular}{cc}
\hline \multicolumn{1}{c}{ Characteristic } & Value* \\
\hline 12-Gy vol $\left(\mathrm{cm}^{3}\right)(\mathrm{n}=1831)$ & $0.054-54.31$ \\
\hline Range & 0.947 \\
\hline Median & 2.66 \\
\hline 75th percentile & $0.076-71.24$ \\
\hline 10-Gy vol $\left(\mathrm{cm}^{3}\right)(\mathrm{n}=1831)$ & 1.26 \\
\hline Range & 3.38 \\
\hline Median & \\
\hline 75th percentile & 2.85 \\
\hline Gradient index $(\mathrm{n}=1831)$ & 3.18 \\
\hline 25th percentile & 3.74 \\
\hline Median & 0.35 \\
\hline P5th percentile & 0.50 \\
\hline Paddick conformity index ( $\mathrm{n}=2049)$ & 0.66 \\
\hline 25th percentile & \\
\hline Median & $3.0-155.2$ \\
\hline 75th percentile & 9.9 \\
\hline Imaging follow-up from SRS (mos) & \\
\hline Range & \\
\hline Median & \\
\hline Values represent numbers of tumors (\%) unless otherwise indicated. & \\
\hline
\end{tabular}

and 0.74 for brain metastases $0.3-0.6 \mathrm{~cm}, 0.7-1.0 \mathrm{~cm}$, $1.1-1.5 \mathrm{~cm}, 1.6-2.0 \mathrm{~cm}$, and $2.1-5.1 \mathrm{~cm}$, respectively. Forty brain metastases were treated in patients with connective tissue disorders, including Sjögren's disease (16), lupus and rheumatoid arthritis (9), lupus alone (8), rheumatoid arthritis (4), ankylosing spondylitis (2), and scleroderma (1).

Brain metastasis outcomes with median treatment parameter values are shown in Table 4. Of all 2200 metastases, $1759(80.0 \%)$ had neither failure nor ARE, 203 (9.2\%) had failure, 118 (5.4\%) had ARE, 30 (1.4\%) had concurrent failure and ARE, and 90 (4.1\%) had indeterminate cause of lesion worsening. Resection confirmed all 30 cases of concurrent failure and ARE, 26 cases of failure, 14 cases of ARE only, and 5 cases of ARE more than 6 months before failure.

TABLE 3. Prescribed dose and target volume by prior or concurrent radiotherapy or SRS

\begin{tabular}{lcccc}
\hline \multicolumn{1}{c}{ Parameter } & None & $\begin{array}{c}\text { Prior } \\
\text { WBRT }\end{array}$ & $\begin{array}{c}\text { Concurrent } \\
\text { WBRT }\end{array}$ & $\begin{array}{c}\text { Prior SRS to } \\
\text { Same Lesion }\end{array}$ \\
\hline Prescribed dose (Gy) & & & & \\
\hline 25th percentile & 18.0 & 18.0 & 18.0 & 17.0 \\
\hline Median & 19.0 & 18.5 & 18.0 & 18.0 \\
\hline 75th percentile & 20.0 & 19.0 & 20.0 & 18.75 \\
\hline Target vol ( $\left.\mathrm{cm}^{3}\right)$ & & & & \\
\hline 25th percentile & 0.06 & 0.06 & 0.07 & 0.32 \\
\hline Median & 0.18 & 0.17 & 0.23 & 0.94 \\
\hline 75th percentile & 0.80 & 0.70 & 1.22 & 3.14 \\
\hline
\end{tabular}

Of the 118 brain metastases developing ARE, 45 (38\%) were asymptomatic, 61 (52\%) symptomatic, and $12(10 \%)$ unknown. Excluding the unknowns, 90\% of ARE cases were symptomatic for brain metastases over $1.5 \mathrm{~cm}$ in maximum diameter at the time of SRS. Seventy-five percent of symptomatic lesions were $1.5 \mathrm{~cm}$ or larger and $75 \%$ of asymptomatic lesions were less than $1.5 \mathrm{~cm}$ in maximum diameter at the time of SRS. We assumed that among the 12 lesions with unknown symptomatology, 2 brain metastases $1.1 \mathrm{~cm}$ or less would have been asymptomatic and 10 that were $1.5 \mathrm{~cm}$ or larger would have been symptomatic.

Table 5 summarizes 1-year cumulative risk of symptomatic ARE, overall ARE, ARE \pm failure, and worst-case ARE by various parameters. For all 2200 brain metastases, the 1-year cumulative incidence of symptomatic ARE and overall ARE was 4\% and 7\%, respectively. The greatest risk factor for ARE appeared to be prior SRS to the same lesion, resulting in 20\% and 37\% 1-year cumulative incidence of symptomatic ARE and overall ARE (Fig. 2 ), respectively. For other parameters reported in Table 5, brain metastases with prior SRS were excluded to eliminate the excess risk seen after repeat SRS. As expected, there was higher risk of ARE with larger lesion diameter (Fig. 3), target volume, prescription isodose volume, 12Gy volume, and 10-Gy volume. However, the 1-year probabilities of symptomatic ARE leveled off at $13 \%-14 \%$ for brain metastasis maximum diameter $>2.1 \mathrm{~cm}$, target volume $>1.2 \mathrm{~cm}^{3}$, prescription isodose volume $>1.8 \mathrm{~cm}^{3}, 12$ Gy volume $>3.3 \mathrm{~cm}^{3}$, and $10-$ Gy volume $>4.3 \mathrm{~cm}^{3}$. There was no significant influence of Paddick conformity index or gradient index on ARE risk with stratification by maxi- 
TABLE 4. Brain metastasis outcomes with treatment parameter median values

\begin{tabular}{|c|c|c|c|c|c|c|}
\hline Outcome & No. of Lesions (\%) & Max Diameter (cm) & Target Vol $\left(\mathrm{cm}^{3}\right)$ & $\begin{array}{c}\text { Prescription } \\
\text { Isodose Vol }\left(\mathrm{cm}^{3}\right)\end{array}$ & $\begin{array}{c}\text { 12-Gy } \\
\text { Vol }\left(\mathrm{cm}^{3}\right)\end{array}$ & $\begin{array}{c}\text { Concurrent } \\
\text { Systemic } \\
\text { Therapy }\end{array}$ \\
\hline No failure, no ARE & $1759(80.0 \%)$ & 0.9 & 0.14 & 0.31 & 0.69 & $61 \%$ \\
\hline Failure* & $203(9.2 \%)$ & 1.3 & 0.74 & 1.16 & 2.57 & $61 \%$ \\
\hline ARE† & $118(5.4 \%)$ & 1.5 & 1.17 & 1.79 & 3.47 & $36 \%$ \\
\hline Concurrent failure \& ARE & $30(1.4 \%)$ & 2.6 & 4.79 & 6.01 & 10.26 & $30 \%$ \\
\hline Indeterminate & $90(4.1 \%)$ & 1.5 & 0.90 & 1.36 & 2.68 & $51 \%$ \\
\hline
\end{tabular}

mum diameter or for brain metastases with target volume $>1.0 \mathrm{~cm}^{3}$. There appeared to be higher risk of ARE for brain metastases from kidney cancer, with 1-year cumulative ARE incidence of $15 \%$, versus $2 \%$ for breast, $5 \%$ for melanoma, and $6 \%$ for lung primaries (Fig. 4). There was no evidence of increased risk of ARE for brainstem or cerebellar lesions, but the median prescription dose was 18.5 Gy for cerebellar lesions and 16.0 Gy for brainstem lesions versus $19.0 \mathrm{~Gy}$ for lobar lesions.

The median time to development of ARE was 7.2 months (range 1.4-38.6 months), with $85 \%$ of cases occurring 3-18 months after SRS (Fig. 5). Of the 118 cases of ARE, 17 (14\%) were treated with resection, showing necrosis only; 2 were treated with bevacizumab; 40 (34\%) were stable (i.e., irreversible) at a median of 7.5 months of additional follow-up after onset of ARE; and 59 (50\%) were reversible, with improved imaging appearance at a median of 5.1 months after onset of ARE (range 1.0-20.3 months). All of the cases of irreversible ARE were diagnosed based on imaging. A course of steroids was given in symptomatic patients, and asymptomatic patients were observed. Among the 99 cases of ARE managed conservatively, the probabilities of imaging improvement at 6,12 , and 18 months after onset of ARE were $40 \%, 57 \%$, and $76 \%$, respectively (Fig. 6). One patient treated with bevacizumab more than 6 months after onset of ARE had temporary shrinkage of an irregular rim-enhancing lesion and surrounding edema, but the lesion worsened rapidly after discontinuation of bevacizumab. Imaging showed a very different-appearing, solid, enhancing tumor. The patient underwent salvage resective surgery and brachytherapy, and pathological examination of the surgical specimen confirmed active tumor. In the other patient treated with bevacizumab, ARE improved with 10 weeks of bevacizumab, and brain imaging findings were stable for 1 year, then worsened; surgery at that point showed both tumor and necrosis.

Only 1 patient with scleroderma had SRS; 19 Gy was administered to a single $0.7 \times 0.6 \times 1.1-\mathrm{cm}$ parietal brain metastasis from lung cancer, with carboplatin, gemcitabine, and vinorelbine administered within 1 week of SRS. The metastasis subsequent demonstrated a complete response, with no ARE or failure as of the last follow-up evaluation 7.8 years later.

Table 6 shows the results of univariate and multivariate analyses by patient among 435 patients with 2200 brain metastases and for the subset of 308 patients with 507 brain metastases with target volume $>1.0 \mathrm{~cm}^{3}$ (corresponding to a maximum diameter of $1.3-5.1 \mathrm{~cm}$, median $2.1 \mathrm{~cm}$ ), to give insight into ARE risk factors for larger lesions. On univariate analysis of all patients, the greatest risk factors for ARE included prior SRS (HR 5.051, 95\% CI 1.935-13.18) and larger target, prescription isodose, and $12-$ and 10-Gy volumes. Among systemic therapies evaluated, only capecitabine/fluorouracil was associated with increased risk of ARE; 69 of the 72 brain metastases in this category were exposed to capecitabine within 1 month of SRS as opposed to fluorouracil, and the 5 cases of ARE in this subset occurred in 4 breast cancer patients and 1 kidney cancer patient treated with capecitabine. Other systemic therapies were not associated with significantly increased risk of ARE; neither were history of hypertension, diabetes, or connective tissue disorder. Univariate analysis of data pertaining to 308 patients and 507 brain metastases with target volume $>1.0 \mathrm{~cm}^{3}$ showed that only prior SRS, kidney primary, capecitabine, and inhibitor therapy were significantly associated with higher ARE risk.

In multivariate analyses including all patients, each of the volume parameters was significantly associated with ARE; only 1 volume parameter at a time was considered, as target, prescription, 12-Gy, and 10-Gy volumes were highly correlated with each other. The other significant risk factors for ARE included prior SRS and capecitabine/ fluorouracil (Table 6). In the multivariate analysis considering only metastases with target volume $>1.0 \mathrm{~cm}^{3}$, risk factors for ARE included prior SRS, kidney primary, connective tissue disorder, and capecitabine/fluorouracil (Table 6).

\section{Discussion}

It has long been recognized that the risk of complications after single-fraction SRS increases with treated volume. In 1979, Kjellberg presented his pioneering dosevolume analysis of complication risk after proton SRS for arteriovenous malformations (AVMs), ${ }^{7}$ later reanalyzed by Barker et al., resulting in much higher risk estimates. ${ }^{1}$ In 1991, Flickinger et al. published dose-volume isoeffect curves predicting a 3\% risk of brain necrosis from Gamma Knife SRS based on modeling that necessarily required many assumptions, along with a statement that future clinical experience in a large number of patients would be needed to test their models. ${ }^{5}$ The final report of Radia- 
TABLE 5. Risk of ARE by lesion characteristics and treatment parameter strata*

\begin{tabular}{|c|c|c|c|c|c|}
\hline \multirow[b]{2}{*}{ Parameter } & \multirow{2}{*}{$\begin{array}{c}\text { Crude Risk of Symptomatic } \\
\text { ARE } \dagger n / n(\%)\end{array}$} & \multicolumn{4}{|c|}{ 1-Year Cumulative Incidence } \\
\hline & & Symptomatic ARE $†$ & ARE & ARE \pm Failure & Worst-Case ARE \\
\hline \multicolumn{6}{|c|}{ Prior or concurrent radiation } \\
\hline None & $30 / 1182(3 \%)$ & $3 \%$ & $5 \%$ & $7 \%$ & $9 \%$ \\
\hline Prior WBRT & $23 / 779(3 \%)$ & $4 \%$ & $6 \%$ & $7 \%$ & $15 \%$ \\
\hline Concurrent WBRT & $8 / 167(5 \%)$ & $8 \%$ & $9 \%$ & $12 \%$ & $16 \%$ \\
\hline Prior SRS $\pm \mathrm{RT}$ & $10 / 72(14 \%)$ & $20 \%$ & $37 \%$ & $40 \%$ & $44 \%$ \\
\hline \multicolumn{6}{|l|}{ Primary site } \\
\hline Breast & $14 / 881(2 \%)$ & $2 \%$ & $2 \%$ & $3 \%$ & $7 \%$ \\
\hline Lung & $22 / 736(3 \%)$ & $4 \%$ & $6 \%$ & $9 \%$ & $14 \%$ \\
\hline Melanoma & $6 / 288(2 \%)$ & $4 \%$ & $5 \%$ & $8 \%$ & $11 \%$ \\
\hline Kidney & $9 / 84(11 \%)$ & $14 \%$ & $15 \%$ & $15 \%$ & $22 \%$ \\
\hline \multicolumn{6}{|l|}{ Location $\ddagger$} \\
\hline Supratentorial lobar & $55 / 1583(3 \%)$ & $4 \%$ & $7 \%$ & $8 \%$ & $13 \%$ \\
\hline Supratentorial deep & $2 / 86(2 \%)$ & $5 \%$ & $7 \%$ & $7 \%$ & $9 \%$ \\
\hline Cerebellar & $3 / 428(1 \%)$ & $1 \%$ & $1 \%$ & $2 \%$ & $6 \%$ \\
\hline Brainstem & $1 / 31(3 \%)$ & $3 \%$ & $3 \%$ & $3 \%$ & $25 \%$ \\
\hline \multicolumn{6}{|l|}{ Max diameter $(\mathrm{cm}) \ddagger$} \\
\hline $0.3-0.6$ & $1 / 611(<1 \%)$ & $<1 \%$ & $1 \%$ & $1 \%$ & $3 \%$ \\
\hline $0.7-1.0$ & $6 / 662(1 \%)$ & $1 \%$ & $4 \%$ & $4 \%$ & $7 \%$ \\
\hline $1.1-1.5$ & $12 / 412(3 \%)$ & $3 \%$ & $7 \%$ & $8 \%$ & $15 \%$ \\
\hline $1.6-2.0$ & $14 / 177(8 \%)$ & $10 \%$ & $12 \%$ & $15 \%$ & $23 \%$ \\
\hline $2.1-5.1$ & $28 / 266(11 \%)$ & $14 \%$ & $15 \%$ & $23 \%$ & $32 \%$ \\
\hline \multicolumn{6}{|l|}{ Target vol $\left(\mathrm{cm}^{3}\right) \ddagger$} \\
\hline$\leq 0.075$ & $0 / 642(0 \%)$ & $0 \%$ & $1 \%$ & $1 \%$ & $2 \%$ \\
\hline $0.076-0.178$ & $2 / 422(<1 \%)$ & $1 \%$ & $2 \%$ & $3 \%$ & $5 \%$ \\
\hline $0.179-0.550$ & $8 / 426(2 \%)$ & $3 \%$ & $6 \%$ & $7 \%$ & $10 \%$ \\
\hline $0.552-1.20$ & $11 / 213(5 \%)$ & $5 \%$ & $11 \%$ & $11 \%$ & $20 \%$ \\
\hline $1.21-28.89$ & $40 / 425(9 \%)$ & $13 \%$ & $13 \%$ & $20 \%$ & $29 \%$ \\
\hline \multicolumn{6}{|c|}{$\begin{array}{l}\text { Prescription isodose volume } \\
\left(\mathrm{cm}^{3}\right) \pm \S\end{array}$} \\
\hline$\leq 0.226$ & $0 / 593(0 \%)$ & $0 \%$ & $1 \%$ & $1 \%$ & $3 \%$ \\
\hline $0.227-0.832$ & $9 / 794(1 \%)$ & $2 \%$ & $4 \%$ & $5 \%$ & $7 \%$ \\
\hline $0.835-1.77$ & $11 / 199(6 \%)$ & $6 \%$ & $11 \%$ & $11 \%$ & $21 \%$ \\
\hline $1.78-3.94$ & $21 / 198(11 \%)$ & $13 \%$ & $16 \%$ & $20 \%$ & $27 \%$ \\
\hline $3.98-35.82$ & $20 / 198(10 \%)$ & $14 \%$ & $14 \%$ & $23 \%$ & $31 \%$ \\
\hline \multicolumn{6}{|l|}{ 12-Gy vol $\left(\mathrm{cm}^{3}\right) \ddagger \mathbb{~}$} \\
\hline$\leq 0.672$ & $2 / 707(<1 \%)$ & $<1 \%$ & $2 \%$ & $2 \%$ & $3 \%$ \\
\hline $0.673-1.84$ & $6 / 531(1 \%)$ & $2 \%$ & $4 \%$ & $5 \%$ & $8 \%$ \\
\hline $1.86-3.30$ & $11 / 177(6 \%)$ & $6 \%$ & $11 \%$ & $11 \%$ & $19 \%$ \\
\hline $3.31-7.00$ & 19/177 (11\%) & $13 \%$ & $16 \%$ & $19 \%$ & $26 \%$ \\
\hline $7.02-35.82$ & $20 / 177(11 \%)$ & $14 \%$ & $15 \%$ & $25 \%$ & $33 \%$ \\
\hline \multicolumn{6}{|l|}{ 10-Gy vol $\left(\mathrm{cm}^{3}\right) \mp \rrbracket$} \\
\hline$\leq 1.17$ & $3 / 883(<1 \%)$ & $<1 \%$ & $2 \%$ & $2 \%$ & $4 \%$ \\
\hline $1.18-2.45$ & $5 / 355(1 \%)$ & $2 \%$ & $5 \%$ & $5 \%$ & $9 \%$ \\
\hline $2.46-4.28$ & 10/177 (6\%) & $5 \%$ & $11 \%$ & $11 \%$ & $19 \%$ \\
\hline $4.31-9.08$ & $20 / 177(11 \%)$ & $14 \%$ & $17 \%$ & $20 \%$ & $26 \%$ \\
\hline
\end{tabular}


TABLE 5. Risk of ARE by lesion characteristics and treatment parameter strata* (continued)

\begin{tabular}{|c|c|c|c|c|c|}
\hline \multirow[b]{2}{*}{ Parameter } & \multirow{2}{*}{$\begin{array}{l}\text { Crude Risk of Symptomatic } \\
\text { ARE } \uparrow n / n(\%)\end{array}$} & \multicolumn{4}{|c|}{ 1-Year Cumulative Incidence } \\
\hline & & Symptomatic ARE† & ARE & ARE \pm Failure & Worst-Case ARE \\
\hline \multicolumn{6}{|c|}{ 10-Gy vol $\left(\mathrm{cm}^{3}\right) \neq \mathbb{I}$ (continued) } \\
\hline $9.11-48.69$ & $20 / 177(11 \%)$ & $14 \%$ & $15 \%$ & $25 \%$ & $33 \%$ \\
\hline Overall & $71 / 2200(3 \%)$ & $4 \%$ & $7 \%$ & $8 \%$ & $13 \%$ \\
\hline \multicolumn{6}{|c|}{$\begin{array}{l}\text { * Refer to Methods for category definitions. } \\
\dagger \text { For ARE cases with unknown symptomatology, } 10 \text { were assumed to be symptomatic and } 2 \text { asymptomatic based on lesion size } \geq 1.5 \mathrm{~cm} \\
\text { versus } \leq 1.1 \mathrm{~cm} \text {. } \\
\text { † Excluding cases of prior SRS with or without RT to the same lesion. } \\
\S \text { Excluding cases for which the prescription isodose contour had any confluence with that of any nearby lesion(s). } \\
\text { ๆ Excluding cases for which the } 10-\text { Gy or half-of-prescription-dose contour had any confluence with that of any nearby lesion(s). }\end{array}$} \\
\hline
\end{tabular}

tion Therapy Oncology Group trial 90-05 made SRS dose recommendations by maximum tumor diameter to limit radionecrosis risk, based on a dose-escalation study in 156 analyzable patients with recurrent primary brain tumors or brain metastases and median survival time of 8.8 months after SRS. ${ }^{13}$ Much clinical experience has been gained since then to allow more in-depth study of ARE incidence, time course, and risk factors.

We chose to evaluate ARE in patients with brain metastases, and rather than consider only symptomatic cases of ARE, we chose to also score overall ARE, including both symptomatic and asymptomatic cases; results are presented both ways in Table 5. Whether imaging-apparent ARE is symptomatic is likely to be influenced by subtleties of lesion location that are recognizable to clinicians but not easily quantifiable, in addition to the size of the area of injury and extent of edema. Furthermore, it is important to be aware of imaging-apparent ARE from a diagnosticdilemma point of view; ARE may be mistaken for tumor progression, resulting in unnecessary salvage treatment with its associated risks, and tumor progression may be mistaken for ARE, resulting in delay in or missed opportunity for appropriate salvage treatment. Similarly, we chose not to focus our analyses on cases of ARE that were managed with surgery because resection may not be appropriate in many patients with significant symptoms, due to considerations such as lesion location and multiplicity, ongoing systemic therapy for cancer, performance status,

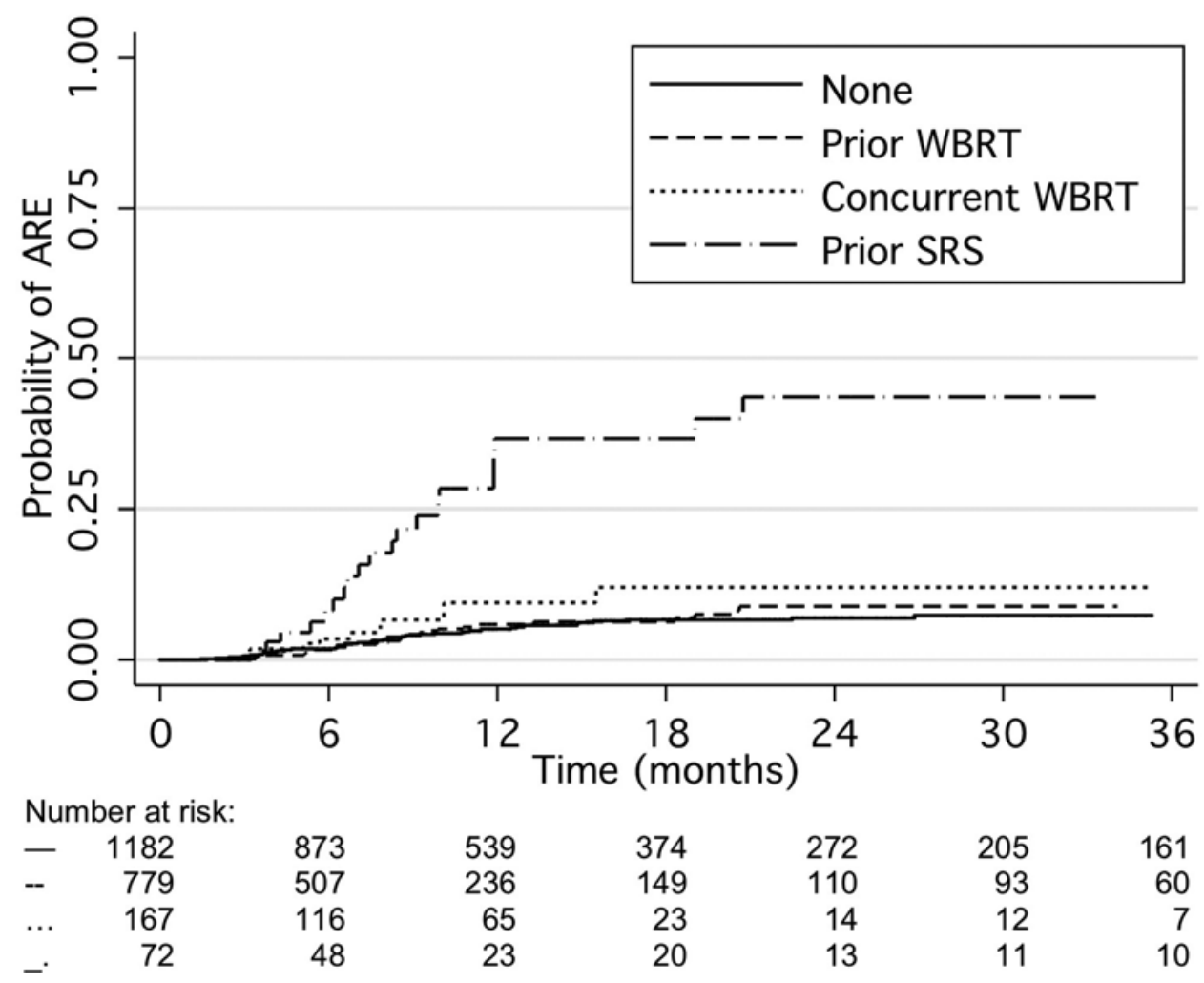

FIG. 2. Kaplan-Meier failure plot of cumulative risk of ARE by other radiation: none, prior WBRT, concurrent WBRT, or prior SRS \pm prior radiotherapy $(p<0.0001)$. The crude rates of ARE were 56/1182 $(5 \%), 31 / 779(4 \%), 11 / 167(7 \%)$, and 20/72 $(28 \%)$, respectively. 


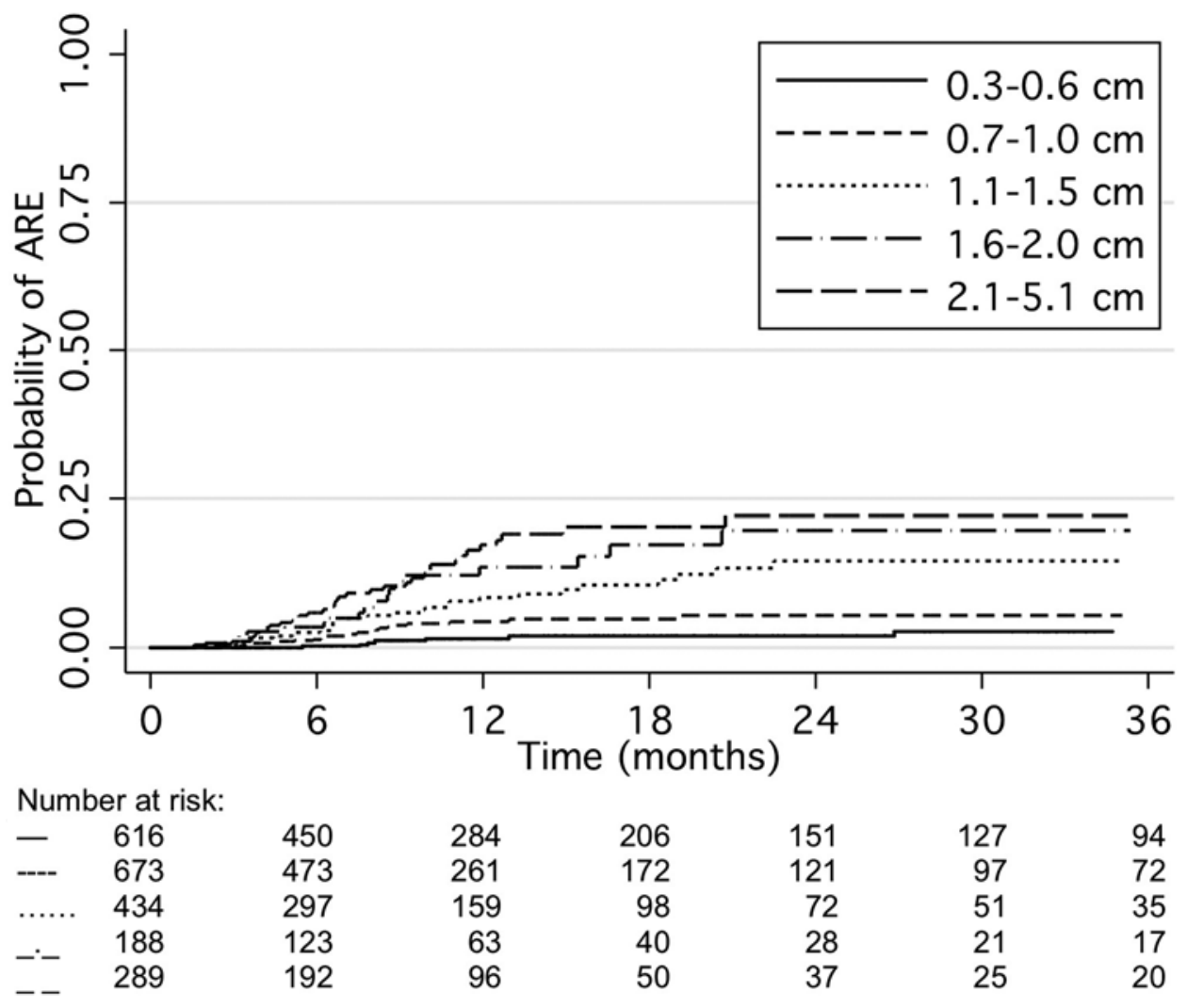

FIG. 3. Kaplan-Meier failure plot of cumulative risk of ARE by maximum diameter, excluding cases of prior radiosurgery to the same lesion ( $p<0.0001)$. The crude rates of ARE were 8/616 (1\%), 22/673 (3\%), 31/434 (7\%), 20/188 (11\%), and $37 / 289(13 \%)$ for the 5 diameter strata.

and prognosis. Only 17 of 71 cases of symptomatic ARE were managed with surgery in our series, which grossly underestimates the incidence of clinically relevant ARE that often requires multiple months of steroid therapy with its attendant side effects.

Our findings differ substantially from those of other authors who have evaluated necrosis risk in non-AVM patients based on SRS dose-volume parameters. ${ }^{3,89}$ Korytko et al. reported much higher risk of necrosis in 105 brain metastases treated with Gamma Knife SRS than we observed (Table 7); their incidence of symptomatic necrosis was $24 \%, 33 \%, 57 \%$, and $55 \%$ for $12-$ Gy volume $0-4.99$, $5-9.99,10-14.99$, and $\geq 15 \mathrm{~cm}^{3}$, respectively; adding cases of asymptomatic necrosis, the corresponding rates were $39 \%, 42 \%, 57 \%$, and $82 \% .{ }^{8}$ We had only $4 \%, 15 \%, 16 \%$, and $11 \%$ risk of ARE and $8 \%, 28 \%, 39 \%$, and $23 \%$ risk of worst-case ARE for the same 12-Gy volume ranges. Minniti et al. found that 10- and 12-Gy volumes were the most predictive parameters for radionecrosis after linear accelerator-based SRS for 310 brain metastases using a 1- to 2-mm margin around gross tumor.9 Table 7 compares their results with our incidence of ARE, ARE \pm failure, and worst-case ARE for the same 10-Gy and 12-Gy volume strata, showing fairly good agreement except that Minniti et al. reported a $47 \%$ risk of necrosis for $10-G y$ volume $>$ $12.6 \mathrm{~cm}^{3}$ or 12-Gy volume $>10.9 \mathrm{~cm}^{3}$ as opposed to our $12 \%-13 \%$ risk of clear ARE, $23 \%$ risk of ARE \pm failure, and $27 \%-28 \%$ risk of worst-case ARE for corresponding volumes. Although our experience with larger volumes is limited, we did have 74, 119, and 136 brain metastases in Table 7's highest-risk subgroups, compared with approximately 77-78 brain metastases per stratum in Minniti et al.'s series.

Flickinger et al. modeled risk of symptomatic complications after radiosurgery for AVMs versus $12-$ Gy volume for 11 different brain locations based on 85 patients with complications and 337 control patients. ${ }^{4}$ Their graphs indicate $\sim 2 \%-42 \%$ risk for $<1-\mathrm{cm}^{3} 12-$ Gy volume and $~$ $2 \%-52 \%$ risk for $\sim 7-\mathrm{cm}^{3} 12$-Gy volume, depending on brain location. In the $3-7-\mathrm{cm}^{3} 12-\mathrm{Gy}$ volume range, our risk of symptomatic ARE was $11 \%$ as opposed to the AVM modeled risk of $\sim 0 \%$ for frontal lobe, $\sim 5 \%$ for occipital lobe, $\sim 15 \%$ risk for thalamus, and $\sim 50 \%$ risk for pons/midbrain. We did not see significant differences in risk of ARE based on hemispheric versus deep brain location. Compared with the AVM experience, our brain metastasis patients appeared to have higher risk of ARE for hemispheric locations but lower risk for brainstem locations. We speculate that brain tissue response to tumor and tumor cell death after SRS may increase risk of ARE in brain metastasis patients compared with AVM patients and that the lower risk of ARE after SRS for brainstem metastases may be explained by our fairly conservative dosing for metastases in this location. Furthermore, func- 


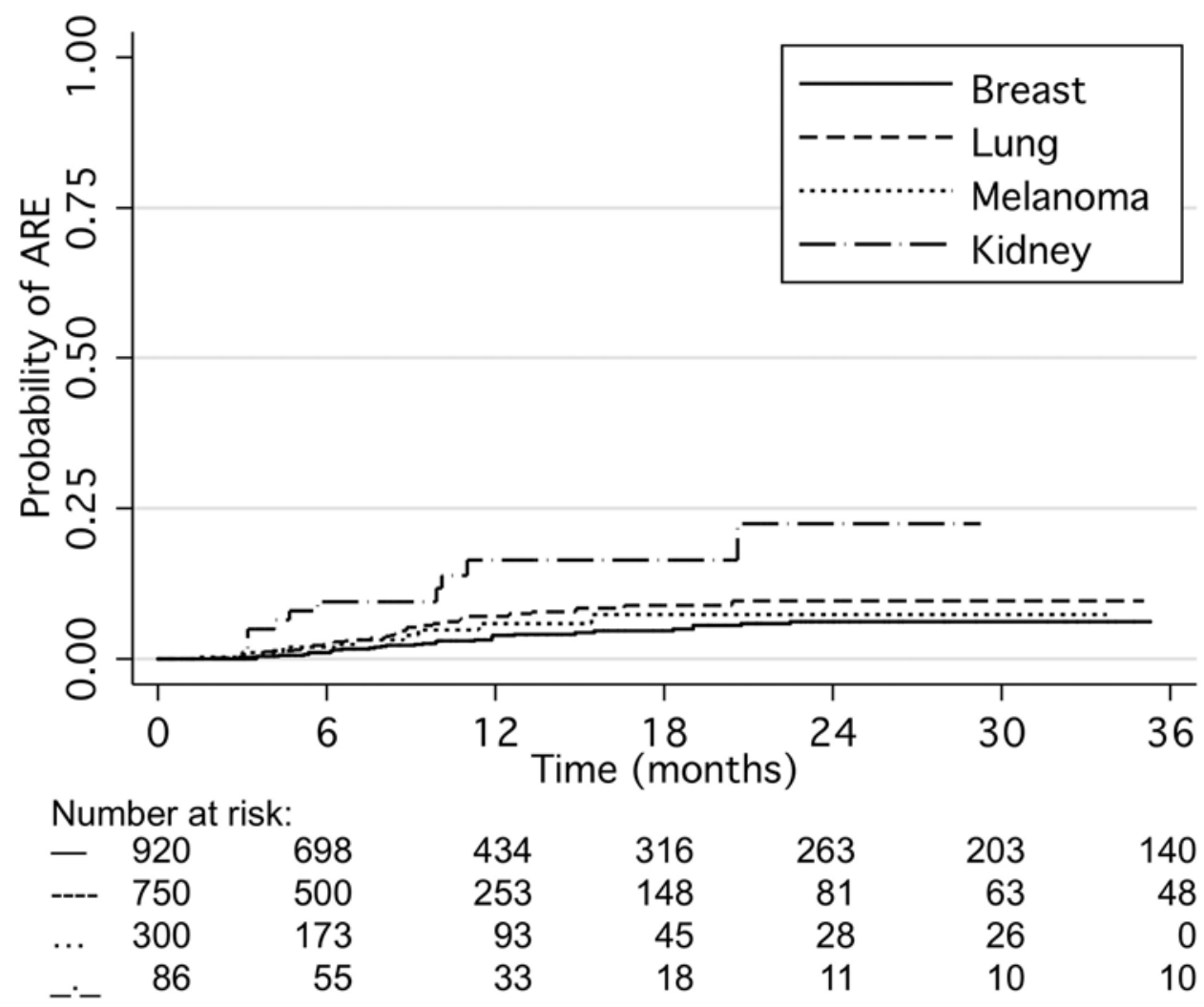

FIG. 4. Kaplan-Meier failure plot of cumulative risk of ARE by primary site, excluding cases of prior radiosurgery to the same lesion. The crude rates of ARE were 32/920 (3\%) for breast, 38/750 (5\%) for lung, 11/300 (4\%) for melanoma, and 11/86 (13\%) for kidney primary disease sites.

tional reorganization could have contributed to the lower complication rate for hemispheric AVMs compared with hemispheric brain metastases.

The selection bias of requiring at least 3 months of imaging follow-up in our series may have modestly increased the apparent probability of ARE by not diluting the denominator with lesions not followed long enough to develop ARE, which is a delayed event. Another limitation of our study is the inherent difficulty in distinguishing between ARE and tumor progression; we addressed this issue with rigorous re-review of serial imaging studies, and we created the indeterminate category to handle the 90 uncertain cases. The retrospective nature of the study could be perceived as a limitation, although it is our opinion that ARE versus failure is best evaluated in retrospect with consideration of the full clinical course, including review of serial imaging to check for sustained growth versus stability or improvement over time without further treatment, as most patients do not undergo surgery for pathological confirmation. We attempted to address our more limited experience with larger targets by providing subset analysis of brain metastases with target volume $>1.0 \mathrm{~cm}^{3}$, corresponding to a median maximum diameter of $2.1 \mathrm{~cm}$.

Strengths of our analysis include the large size of the data set, allowing for meaningful multivariate analysis, and the rigorous re-review of serial follow-up imaging studies for consistent scoring by lesion of ARE, failure, or indeterminate cause of lesion worsening. We consider
ARE and symptomatic ARE to be the most relevant endpoints, but for completeness, we also report risks of ARE \pm failure and worst-case ARE including the indeterminate cases. We expect that worst-case ARE is a gross overestimate, as failure was twice as prevalent as ARE-overall and for each of the brain metastasis diameter subgroups shown in Fig. 3.

The time course of ARE has not been described thoroughly in the literature previously for a large series of brain metastases treated with SRS. We found a wide range in the time of onset of ARE and in time to improvement of ARE, and at least $75 \%$ probability of improvement over time in conservatively managed ARE.

We also provide a first step in considering the possible influence of systemic therapy on risk of ARE by evaluating cytotoxic, inhibitor, and antibody therapy within 1 month of SRS. With the exception of capecitabine, systemic therapy within 1 month of SRS did not appear to increase the risk of ARE on univariate or multivariate analysis, and neither did hypertension or diabetes. History of connective tissue disorder was not associated with risk of ARE overall, but it was significant on multivariate analysis for targets $>1.0 \mathrm{~cm}^{3}$, with a modest HR of 1.386 and $95 \%$ CI 1.022-1.880, suggesting that connective tissue disorder should not be a contraindication for SRS.

It is common practice to prescribe lower doses for larger brain metastases treated with SRS to mitigate the known risk of ARE; we hypothesize that this practice explains the 


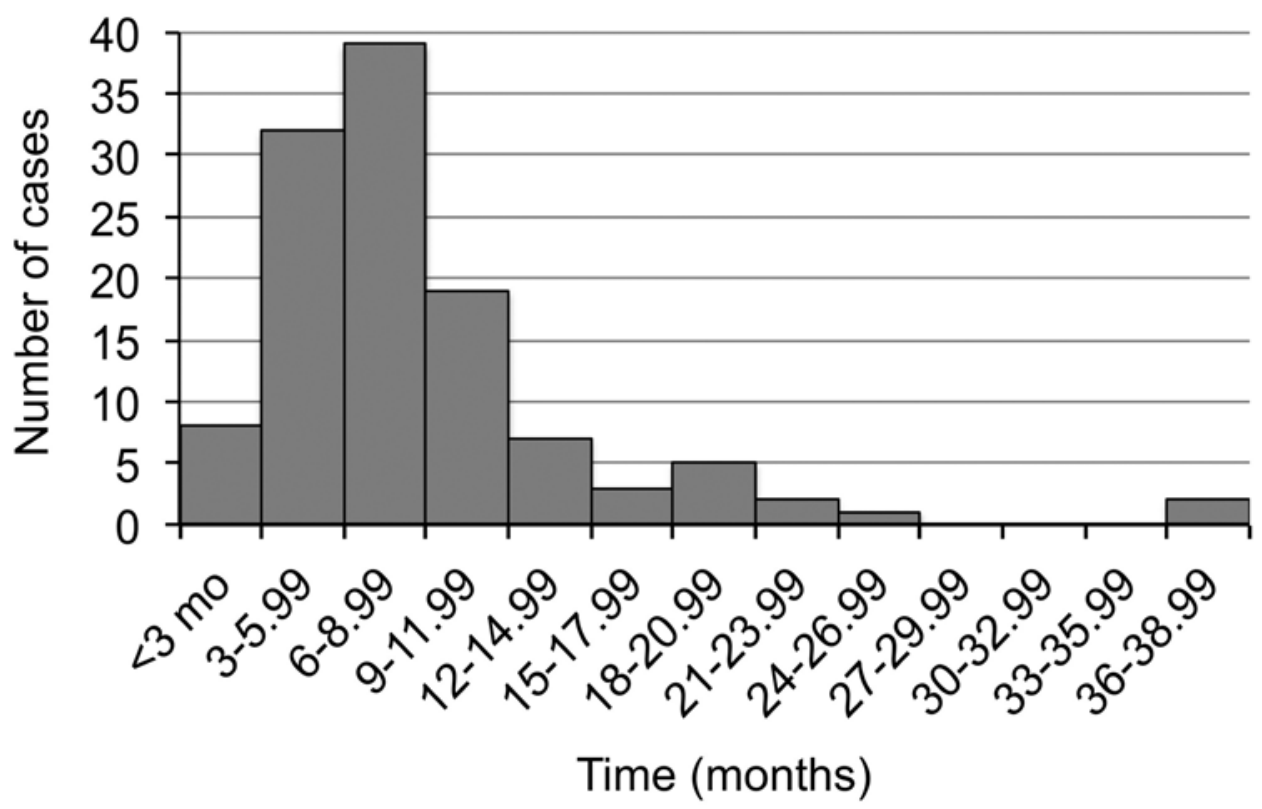

FIG. 5. Bar graph of number of cases of ARE versus months from the date of stereotactic radiosurgery. The median time to onset of ARE on imaging was 7.2 months, with a range of 1.4-38.6 months; $85 \%$ of cases occurred 3-18 months after SRS.

leveling off of ARE risk in our series for brain metastases with a maximum diameter in the range of $2.1-5.1 \mathrm{~cm}$. Target volume, prescription isodose volume, 12-Gy volume, and $10-$ Gy volume were each significantly associated with risk of ARE, and no single one of these parameters stood out as being a best predictor. A future analysis of freedom from progression is planned to inform treatment selection and SRS dose prescription, taking into account the competing risks of failure and ARE.

\section{Conclusions}

The incidence, time course, and risk factors for ARE after SRS were studied in 2200 brain metastases and 435

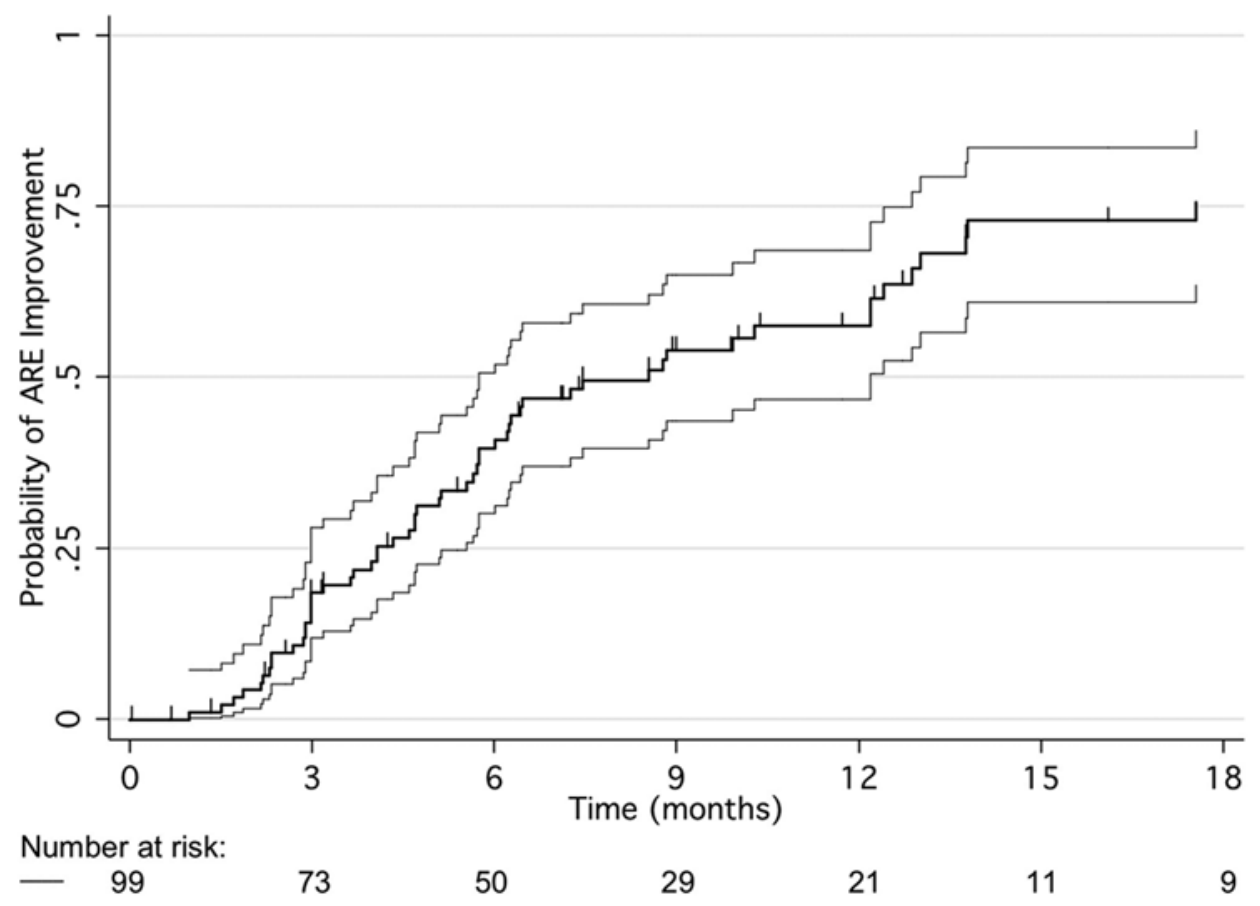

FIG. 6. Kaplan-Meier failure plot of the cumulative probability of imaging improvement of ARE with $95 \%$ confidence intervals in 99 cases not managed with surgery or bevacizumab. The probabilities of improvement were $40 \%, 57 \%, 76 \%$, and $84 \%$ at $6,12,18$, and 24 months after onset of ARE (median 7.5 months). 
TABLE 6. Univariate and multivariate Cox proportional hazards analyses by patient for risk of ARE*

\begin{tabular}{|c|c|c|c|c|}
\hline \multirow[b]{2}{*}{ Parameter } & \multicolumn{2}{|c|}{$\begin{array}{c}\text { Considering All Metastases } \\
\text { (435 pts) }\end{array}$} & \multicolumn{2}{|c|}{$\begin{array}{c}\text { Considering Only Metastases w/ } \\
\text { Target Vol > } 1.0 \mathrm{~cm}^{3} \text { (308 pts) }\end{array}$} \\
\hline & $\mathrm{HR}$ & $95 \% \mathrm{Cl}$ & $\mathrm{HR}$ & $95 \% \mathrm{Cl}$ \\
\hline \multicolumn{5}{|l|}{ Univariate analyses } \\
\hline Prior WBRT vs SRS alone & 1.457 & $0.875-2.424$ & 1.335 & $0.938-1.901$ \\
\hline Concurrent WBRT vs SRS alone & 1.714 & $0.820-3.583$ & 0.954 & $0.767-1.187$ \\
\hline Prior SRS \pm WBRT vs SRS alone & 5.051 & $1.935-13.18$ & 4.755 & $2.928-7.722$ \\
\hline Prescribed dose (Gy) & 0.814 & $0.731-0.908$ & 1.161 & $0.990-1.361$ \\
\hline Target vol $\left(\mathrm{cm}^{3}\right)$ & 1.087 & $1.044-1.132$ & 0.989 & $0.957-1.021$ \\
\hline Prescribed isodose vol $\left(\mathrm{cm}^{3}\right) \dagger$ & 1.072 & $1.040-1.106$ & 0.997 & $0.971-1.024$ \\
\hline 12-Gy vol $\left(\mathrm{cm}^{3}\right) \ddagger$ & 1.049 & $1.030-1.069$ & 0.982 & $0.959-1.005$ \\
\hline 10-Gy vol $\left(\mathrm{cm}^{3}\right) \ddagger$ & 1.039 & $1.024-1.054$ & 0.988 & $0.970-1.006$ \\
\hline Kidney primary§ & 0.516 & $0.001-285.4$ & 2.295 & $1.510-3.489$ \\
\hline Hypertension§ & 0.992 & $0.653-1.507$ & 0.958 & $0.762-1.204$ \\
\hline Diabetes mellitus§ & 1.055 & $0.521-2.138$ & 1.037 & $0.855-1.259$ \\
\hline Connective tissue disorder§ & 0 & $0-2101$ & 0.837 & $0.710-0.986$ \\
\hline Systemic therapy w/in $1 \mathrm{mo} \S$ & 0.561 & $0.374-0.842$ & 0.819 & $0.631-1.063$ \\
\hline Cytotoxic therapy w/in 1 moß & 0.666 & $0.431-1.027$ & 0.820 & $0.647-1.039$ \\
\hline Taxane§ & 0.262 & $0.111-0.617$ & 0.421 & $0.354-0.502$ \\
\hline Platin§ & 0.840 & $0.518-1.363$ & 0.621 & $0.433-0.891$ \\
\hline Temozolomide§ & 0 & $0-0.065$ & 0 & $0-3558$ \\
\hline Gemcitabine§ & 0.801 & $0.370-1.733$ & 0.803 & $0.327-1.972$ \\
\hline Vinca alkaloid§ & 1.315 & $0.532-3.252$ & 1.246 & $0.583-2.661$ \\
\hline Antifolate§ & 1.152 & $0.854-1.555$ & 1.036 & $0.793-1.352$ \\
\hline Capecitabine/5-FU§ & 2.227 & $1.333-3.723$ & 3.340 & $2.733-4.081$ \\
\hline Topoisomerase inhibitor§ & 0 & $0-0.001$ & 0.879 & $0.671-1.152$ \\
\hline Inhibitor therapy w/in 1 moß & 1.066 & $0.546-2.082$ & 2.133 & $1.318-3.452$ \\
\hline Antibody therapy w/in 1 moß & 0.789 & $0.412-1.514$ & 0.967 & $0.631-1.484$ \\
\hline \multicolumn{5}{|l|}{ Multivariate analysis } \\
\hline Prior or concurrent WBRT vs SRS alone & 1.177 & $0.704-1.969$ & 1.030 & $0.733-1.447$ \\
\hline Prior SRS \pm WBRT vs SRS alone & 3.744 & $1.298-10.80$ & 4.899 & $2.675-8.973$ \\
\hline Target vol $\left(\mathrm{cm}^{3}\right)$ & 1.094 & $1.037-1.155$ & - & - \\
\hline Kidney primary & - & - & 1.933 & $1.166-3.204$ \\
\hline Connective tissue disorder & - & - & 1.386 & $1.022-1.880$ \\
\hline Taxane & 0.255 & $0.112-0.581$ & 0.404 & $0.323-0.506$ \\
\hline Capecitabine/5-FU & 2.614 & $1.497-4.565$ & 3.614 & $2.896-4.510$ \\
\hline \multicolumn{5}{|c|}{$\begin{array}{l}\text { 5-FU = fluorouracil. } \\
\text { * Statistically significant results are shown in boldface type. } \\
\text { † Excluding cases for which the prescription isodose contour had any confluence with that of any nearby lesion(s). } \\
\text { † Excluding cases for which the } 10 \text {-Gy or half-of-prescription-dose contour had any confluence with that of any nearby lesion(s). } \\
\text { § } 0=\text { no; } 1=\text { yes; if applicable, unknown cases excluded. } \\
\text { I Results of the multivariate analysis for all metastases were very similar replacing target volume with prescription isodose volume (HR } 1.074 \text {, } \\
95 \% \mathrm{Cl} 1.028-1.121), 12 \text {-Gy volume (HR 1.048, } 95 \% \mathrm{Cl} 1.023-1.073) \text {, or } 10 \text {-Gy volume (HR } 1.038,95 \% \mathrm{Cl} 1.018-1.058) \text {. }\end{array}$} \\
\hline
\end{tabular}

patients with at least 3 months of imaging follow-up. By lesion, the median time to ARE was 7.2 months, $85 \%$ of cases occurred 3-18 months after SRS, and the probabilities of imaging improvement were $40 \%, 57 \%$, and $76 \%$ at 6,12 , and 18 months after onset of ARE. The 1-year probabilities of symptomatic ARE were 3\% after SRS alone, $4 \%$ for SRS given after previous WBRT, $8 \%$ after SRS combined with WBRT, and $20 \%$ after repeat SRS to same lesions. Excluding cases of repeat SRS, the 1-year probabilities of symptomatic ARE increased rapidly with target and treatment volume but leveled off at 13\%-14\% for brain metastasis maximum diameter $>2.1 \mathrm{~cm}$, target volume $>1.2 \mathrm{~cm}^{3}$, prescription isodose volume $>1.8 \mathrm{~cm}^{3}$, $12-$ Gy volume $>3.3 \mathrm{~cm}^{3}$, and $10-$ Gy volume $>4.3 \mathrm{~cm}^{3}$. No single volume or dose-volume parameter stood out as being a best predictor of ARE. Risk estimates are reported by lesion and treatment parameter strata to aid in decision making and patient counseling. 
TABLE 7. Necrosis/ARE incidence after SRS for brain metastases: results of other dose-volume analyses compared with the current study

\begin{tabular}{|c|c|c|c|c|c|}
\hline \multirow[b]{2}{*}{ Parameter \& Strata } & \multirow{2}{*}{$\begin{array}{c}\text { Korytko et al. }{ }^{7} \\
n / n(\%)\end{array}$} & \multirow{2}{*}{$\begin{array}{c}\text { Minniti et al. }{ }^{8} \\
n / n(\%)\end{array}$} & \multicolumn{3}{|c|}{ Current Study* } \\
\hline & & & ARE n/n (\%) & ARE \pm Failure $n / n(\%)$ & Worst-Case ARE n/n (\%) \\
\hline Overall & $47 / 105(45 \%)$ & $75 / 310(24 \%)$ & $106 / 1838(6 \%)$ & $133 / 1838(7 \%)$ & $201 / 1838(11 \%)$ \\
\hline 10-Gy vol $\left(\mathrm{cm}^{3}\right)$ & & By quartile & & & \\
\hline$<4.5$ & - & $(3 \%)$ & $52 / 1457(4 \%)$ & $54 / 1457(4 \%)$ & $93 / 1457(6 \%)$ \\
\hline $4.5-7.7$ & - & $(11 \%)$ & $24 / 148(16 \%)$ & $30 / 148(20 \%)$ & $40 / 148(27 \%)$ \\
\hline $7.8-12.6$ & - & $(24 \%)$ & $14 / 97(14 \%)$ & 18/97 (19\%) & $31 / 97(32 \%)$ \\
\hline$>12.6$ & - & $(47 \%)$ & $16 / 136(12 \%)$ & $31 / 136(23 \%)$ & $37 / 136(27 \%)$ \\
\hline 12-Gy vol $\left(\mathrm{cm}^{3}\right)$ & & By quartile & & & \\
\hline$<3.3$ & - & $(3 \%)$ & $52 / 1454(4 \%)$ & $54 / 1454(4 \%)$ & $93 / 14546 \%)$ \\
\hline $3.3-5.9$ & - & $(11 \%)$ & $23 / 150(15 \%)$ & $29 / 150(19 \%)$ & $40 / 150(27 \%)$ \\
\hline $6.0-10.9$ & - & $(24 \%)$ & $16 / 115(14 \%)$ & $23 / 115(20 \%)$ & $35 / 115(30 \%)$ \\
\hline$>10.9$ & - & $(47 \%)$ & $15 / 119(13 \%)$ & $27 / 119(23 \%)$ & $33 / 119(28 \%)$ \\
\hline \multicolumn{6}{|l|}{ 12-Gy vol $\left(\mathrm{cm}^{3}\right)$} \\
\hline$<4.99$ & $29 / 75(39 \%)$ & - & $66 / 1558(4 \%)$ & $73 / 1558(5 \%)$ & $120 / 1558(8 \%)$ \\
\hline $5-9.99$ & $5 / 12(42 \%)$ & - & $24 / 155(15 \%)$ & $29 / 155(19 \%)$ & $44 / 155(28 \%)$ \\
\hline $10-14.99$ & $4 / 7(57 \%)$ & - & $8 / 51(16 \%)$ & $17 / 51(33 \%)$ & $20 / 51(39 \%)$ \\
\hline$\geq 15$ & $9 / 11(82 \%)$ & - & $8 / 74(11 \%)$ & $14 / 74(19 \%)$ & $17 / 74(23 \%)$ \\
\hline
\end{tabular}

* Including lesions treated with repeat radiosurgery, excluding cases with inevaluable 10- or 12-Gy volumes. Refer to Methods for category definitions.

\section{References}

1. Barker FG II, Butler WE, Lyons S, Cascio E, Ogilvy CS, Loeffler JS, et al: Dose-volume prediction of radiation-related complications after proton beam radiosurgery for cerebral arteriovenous malformations. J Neurosurg 99:254-263, 2003

2. Chao ST, Ahluwalia MS, Barnett GH, Stevens GH, Murphy ES, Stockham AL, et al: Challenges with the diagnosis and treatment of cerebral radiation necrosis. Int J Radiat Oncol Biol Phys 87:449-457, 2013

3. Chin LS, Ma L, DiBiase S: Radiation necrosis following gamma knife surgery: a case-controlled comparison of treatment parameters and long-term clinical follow up. J Neurosurg 94:899-904, 2001

4. Flickinger JC, Kondziolka D, Lunsford LD, Kassam A, Phuong LK, Liscak R, et al: Development of a model to predict permanent symptomatic postradiosurgery injury for arteriovenous malformation patients. Int J Radiat Oncol Biol Phys 46:1143-1148, 2000

5. Flickinger JC, Lunsford LD, Wu A, Kalend A: Predicted dose-volume isoeffect curves for stereotactic radiosurgery with the 60Co gamma unit. Acta Oncol 30:363-367, 1991

6. Gerosa M, Nicolato A, Foroni R, Zanotti B, Tomazzoli L, Miscusi M, et al: Gamma knife radiosurgery for brain metastases: a primary therapeutic option. J Neurosurg 97 (5 Suppl):515-524, 2002

7. Kjellberg RN: Isoeffective dose parameters for brain necrosis in relation to proton radiosurgical dosimetry, in Szikla G (ed): INSERM Symposium on Stereotactic Irradiations. INSERM Symposia, Vol 12. Amsterdam: Elsevier, 1979, pp $157-166$

8. Korytko T, Radivoyevitch T, Colussi V, Wessels BW, Pillai K, Maciunas RJ, et al: 12 Gy gamma knife radiosurgical volume is a predictor for radiation necrosis in non-AVM intracranial tumors. Int J Radiat Oncol Biol Phys 64:419-424, 2006

9. Minniti G, Clarke E, Lanzetta G, Osti MF, Trasimeni G, Bozzao A, et al: Stereotactic radiosurgery for brain metastases: analysis of outcome and risk of brain radionecrosis. Radiat Oncol 6:48, 2011

10. Paddick I: A simple scoring ratio to index the conformity of radiosurgical treatment plans. Technical note. J Neurosurg 93 (Suppl 3):219-222, 2000

11. Paddick I, Lippitz B: A simple dose gradient measurement tool to complement the conformity index. J Neurosurg 105 Suppl:194-201, 2006

12. Petrovich Z, Yu C, Giannotta SL, O’Day S, Apuzzo ML: Survival and pattern of failure in brain metastasis treated with stereotactic gamma knife radiosurgery. J Neurosurg 97 (5 Suppl):499-506, 2002

13. Shaw E, Scott C, Souhami L, Dinapoli R, Kline R, Loeffler J, et al: Single dose radiosurgical treatment of recurrent previously irradiated primary brain tumors and brain metastases: final report of RTOG protocol 90-05. Int J Radiat Oncol Biol Phys 47:291-298, 2000

\section{Author Contributions}

Conception and design: Sneed. Acquisition of data: Sneed, Mendez, Vemer-van den Hoek, Ma, Fogh, Nakamura,

McDermott. Analysis and interpretation of data: Sneed, Seymour, Ma. Drafting the article: Sneed. Critically revising the article: Sneed, Seymour, Ma, Nakamura. Reviewed submitted version of manuscript: Sneed, Mendez, Vemer-van den Hoek, Seymour, Ma, Molinaro, Fogh, Nakamura. Approved the final version of the manuscript on behalf of all authors: Sneed. Statistical analysis: Sneed, Molinaro.

\section{Supplemental Information}

\section{Previous Presentation}

Presented in part at the 16th International Meeting of the Leksell Gamma Knife Society, Sydney, Australia, March 27, 2012, and at the 54th Annual Meeting of the American Society for Radiation Oncology (ASTRO), Boston, Massachusetts, October 31, 2012.

\section{Correspondence}

Penny K. Sneed, Department of Radiation Oncology, UCSF, 505 Parnassus Ave., Rm. L75, Box 0226, San Francisco, CA 941430226.email: psneed@radonc.ucsf.edu. 